\title{
Resistiendo con las Escrituras. Judeoportugueses y el Antiguo Testamento en procesos inquisitoriales americanos (1580-1640)*
}

\section{Ignacio Chuecas Saldías}

Instituto de Historia

Pontificia Universidad Católica de Chile

El estudio que se desarrolla a continuación se enmarca en el contexto de una propuesta mayor que intenta rastrear los indicios de las agencias religiosas entre los portugueses procesados como judaizantes por los tribunales del Santo Oficio americano durante la modernidad temprana. Notablemente, a raíz de los trabajos de António José Saraiva, durante la segunda mitad del siglo XX se instala, no sin controversia, en el medio académico la noción según la cual los juicios inquisitoriales contra cristianos nuevos portugueses representaron una suerte de máquina productora de judaizantes, cuya motivación primaria se encontraba en la confiscación de los bienes de un segmento particularmente próspero de la sociedad ibérica (Révah; Saraiva; Saraiva). Es en este horizonte que se torna importante analizar los aspectos religiosos, particularmente los reflejados en los ámbitos literarios, que caracterizaron a hombres y mujeres perseguidos por la institución inquisitorial. Por este motivo, este estudio indaga en el empleo de textos procedentes de la Biblia hebrea entre judaizantes portugueses en la América española durante el período de la llamada unión de las dos Coronas (1580-1640). Fundamentalmente se trata de incursionar en dos aspectos centrales: el uso de textos bíblicos como medio de fortalecer y desarrollar la propia identidad judaizante; y por otra parte, el empleo de las Escrituras como arma apologética en el contexto de los ataques inquisitoriales para desvirtuar la ley de Moisés.

Al mismo tiempo, esta contribución está pensada como homenaje al trabajo de Carlo Ginzburg al conmemorarse, el año 2016, 40 años de la publicación de su emblemático libro Il formaggio e i vermi (1976). En esta obra fundamental, Ginzburg no solamente desenreda la compleja madeja de los tratos de Domenico Scandella (conocido como Menocchio) con el tribunal del Santo Oficio de la Inquisición sino que al mismo tiempo intenta desentrañar la matriz cultural y literaria, en especial el sustrato bíblico, que soportaba las proposiciones heréticas del molinero protagonista.

\section{Modernidad y metatexto bíblico}

Se ha indagado relativamente poco en relación con el papel que desempeñaron las escrituras judeocristianas en la conformación de la cultura y

\footnotetext{
* Este artículo forma parte del Proyecto Fondecyt posdoctoral No 3170453: "Diáspora de la nación portuguesa en tierras del rey de España: el caso del virreinato peruano durante el siglo XVII".
} 
las mentalidades en la sociedad europea moderna (Reventlow; Hassán; Boynton \& Reilly).

El problema del acceso al texto bíblico (en especial al Antiguo Testamento) representa un factor omnipresente durante la modernidad temprana. El concilio de Trento restringe la lectura individual del texto como reacción ante las iniciativas de la reforma protestante. Las dificultades de acceso implican varios momentos: las ediciones efectivamente disponibles, las variantes textuales, las traducciones en lenguas vernáculas, y la inclusión de libros considerados deuterocanónicos o apócrifos, entre otras.

Quizás el problema mayor, en relación con las necesidades de los círculos judaizantes, suceda en torno a la primacía de la Vulgata de Jerónimo como texto canónico exclusivo promovido por la contrarreforma tridentina ${ }^{1}$. Esta opción de los padres conciliares encierra varios momentos relevantes en cuanto a la factibilidad de su uso por parte de nuestros actores. En general se han de considerar varios aspectos que determinaban la postura de los judaizantes en relación con la Vulgata: su fidelidad a la Biblia hebrea, la literalidad de su traducción, la calidad de la lengua latina, las críticas y alternativas a ella emanadas desde los círculos humanistas, etc. Estos factores, como se verá, resultan particularmente evidentes en la documentación generada por el emblemático judaizante hispano-portugués, residente en la Nueva España, Luis de Carvajal (1566-1596) y su entorno.

\section{Resistiendo con las Escrituras}

La manera en que pretendo enfocar la problemática resulta de la conceptualización de las categorías metodológicas representadas por los empleos apologéticos, controversiales y como medio de reafirmación identitaria mediante textos bíblicos veterotestamentarios. Estas vías de recurso a las escrituras del Antiguo Testamento parecen haber sido, al igual que en el caso de Domenico Scandella documentado por Carlo Ginzburg, extremadamente usuales entre los judaizantes portugueses en la América hispana.

En el marco de la Gran Complicidad de la Ciudad de los Reyes en la década de 1630 (Montesinos; Pulido Serrano; Schaposchnik) fue procesado por el santo oficio limeño el comerciante portugués Luis de Lima. Este reo declaró en su proceso que se había concertado con dos compañeros de prisión para hacer ayunos de la ley de Moisés

"... y que cuando los hicieron rezaban unas oraciones contenidas en un libro intitulado La paciencia de Zárate que una era de la reina Ester, otra del rey Manasés, otra

\footnotetext{
1 Se trata de una situación que intentará ser revertida de manera simbólica por la comunidad judeoportuguesa de Ferrara (Italia) por medio de su famosa y fundamental traducción del Antiguo Testamento al romance español (Biblia de Ferrara 1553; Hassán, 1994). Al respecto es posible advertir que a lo largo de este artículo las citas de pasajes bíblicos, y esto es particularmente importante de notar en relación con la numeración de los Salmos, se hace a base de los parámetros que rigen para la Vulgata de Jerónimo, porque esta es la sistematización del texto que conocieron (y emplearon) los sujetos de este estudio.
} 
de Mardoqueo = y la de Ester comienza - Señor mío que solo eres nuestro rey, favorece a esta pobre solitaria $-y$ fue prosiguiendo con ella de memoria hasta acabarla y tuvo dos planas y media - La de Manasés comienza por señor todopoderoso Dios de nuestros padres Abrahan, Isac y Jacob y la prosiguió por otras dos planas de memoria = La de Mardoqueo comienza Señor, Señor Rey omnipotente y la prosiguió por una plana de memoria y las dichas oraciones las rezaban con intención de judíos todos tres..." (Proceso Luis de Lima, 1639-1666: 222v-223).

En su testimonio Luis de Lima hace referencia a tres textos contenidos en la Vulgata2: Ester XIII, 9-17; XIV, 3-19; y la Oración de Manasés, texto apócrifo incluido como adición a los libros de Crónicas. Además confesó que rezaba también las oraciones de David, Jonás y Tobías (probablemente 1 Crónicas XVII, 16-27; Tobías III, 13-23; y Jonás II, 2-10), según la versión del mismo libro de La paciencia de Zárate, "y las refirió de memoria y tuvieron más de dos planas, y que las rezaba por oraciones de la ley de Moisés..." (Proceso Luis de Lima, 1639-1666: 223v). Consultando la obra aludida por Luis es posible citar, a modo de ejemplo, el pasaje relativo a la oración de Mardoqueo:

\begin{abstract}
"Señor, Señor, rey omnipotẽte, todas las colas eftan debaxo de tu mando y poder, fin auer cola dellas que pueda hazer refiftencia a tu voluntad: Si efta fuere de faluar efte tu pueblo de Irrael, Señor foys de todo, y no ay quien leuante lança contra vueftra mageftad, vos feñor lo fabeys todo, y $\tilde{\mathrm{q}}$ el no auer yo adorado al Toberuio de Aman, ni fue roberuia, ni por afrẽtalle, ni por vanagloria: porque por la falud del pueblo y por fu paz, no digo yo leuantarme pero los pies eftaua prefto de befalle, pero tuue miedo de dar la honra y adoracion a vn hombre, que a folo Dios deuemos, y adorar a otro, q a folo mi Dios. Y agora Señor, y rey mio, Dios de Abraham, ten piedad de tu pueblo, $\tilde{\mathrm{q}}$ nos quieren deftruyr nuetros enemigos y acabar vuetra heredad. No delampareys ni tengays en poco la hazienda que redemiftes, y facaftes para vos de Egypto. Oyd Señor mi oracion, y fauoreced a vueftra gẽte y bolued en gozo nueftras lagrimas, para q̃ viuiẽdo adoremos alabemos vro fancto nõbre, y no tapeys las bocas de los que cantã vueftras alabanças" (Zárate, 1592, Libro II: 262v-263).
\end{abstract}

Como se observa, se trata efectivamente de la traducción al romance del pasaje de Ester XIII, 9-17, que comienza exactamente con las mismas palabras que Luis de Lima recordaba en su testimonio ("La de Mardoqueo comienza Señor, Señor Rey omnipotente..."). El recurso a la obra de Zárate se explica a partir de la gran dificultad que se presentaba a quienes no eran latinistas

\footnotetext{
2 Que ha encontrado traducidos al romance en la obra Discvrsos de la paciencia Chriftiana del agustino Hernando de Zárate publicada en 1592.
} 
para acceder al texto bíblico y la necesidad de disponer de traducciones al romance de, al menos, pasajes del Antiguo Testamento (Amiel 509-534; Castillo Gómez; Vega). Como se verá en el caso de Luis de Carvajal, parece haber sido una práctica común entre los judaizantes el recopilar y emplear oraciones bíblicas atribuidas a personajes emblemáticos del pasado de Israel, cuyos contextos vitales (como es el caso de Mardoqueo, Ester, Jonás, Tobías y otros, todos ellos sobreviviendo en el mundo de los gentiles) pueda guardar semejanza con el de nuestros protagonistas.

Diego Díaz Nieto, judío portugués, procesado por segunda vez por el tribunal de México en 1600, confesó que habría nacido y crecido en la judería de Ferrara (su padre, también procesado, era natural de Oporto). Al declararse judío no bautizado, manifiesta su intención de convertirse al cristianismo, para ello solicita a los inquisidores esclarecer previamente sus dudas teológicas. Con este propósito requiere le proporcionen una versión hebrea de las Escrituras, a partir de esto formula sus interrogantes en relación con el Cristianismo. Principalmente se trata de preceptos contenidos en el Antiguo Testamento (fundamentalmente en los libros del Éxodo y Deuteronomio) y que los cristianos ostensiblemente no respetan:

\begin{tabular}{|l|l|}
\hline \multicolumn{1}{|c|}{ Dudas teológicas expresadas por Diego Díaz Nieto } & \multicolumn{1}{|c|}{ Libro } \\
\hline 1) Precepto de circuncisión & Éxodo \\
\hline 2) Idolatría: culto a las imágenes. & Éxodo \\
\hline 3) Guarda del sábado. & Éxodo \\
\hline $\begin{array}{l}\text { 4) Prohibición de comer carne de bestias con pezuña } \\
\text { partida }\end{array}$ & Éxodo \\
\hline 5) Mesías y venida del falso profeta. & Deuteronomio \\
\hline 6) Prohibición de pronunciar el nombre de Dios. & Éxodo \\
\hline
\end{tabular}

Fuente: Según Uchmany 1992: 252-254.

Adicionalmente exige, de parte de los inquisidores, tres aclaraciones específicas relativas a la doctrina cristiana (Uchmany 254-255): 1) que se pruebe escrituralmente el dogma de la Trinidad; 2 ) que analicen los salmos que se refieren a la venida del rey Mesías (menciona los Salmos II y XLIX "... y de otros que se acordará"); 3) y que se explique, también desde la Escritura, el parto virginal de María. Al cabo de los debates exegéticos, que lamentablemente no se encuentran en los autos, el escribano registró que el reo

"... dijo que está muy contento y lo ha estado toda esta noche de haber visto y entendido los lugares de la Escritura que anunciaban y significaban el verdadero Mesías, Christo nuestro Redemptor y ansí le tiene y cree por tal..." (Uchmany 256).

En el caso de Díaz Nieto, parece evidente que todo este procedimiento representa una estrategia orientada a conseguir la propia libertad de las 
cárceles del Santo Oficio para lograr, posteriormente, una fuga y retorno a las juderías italianas ${ }^{3}$.

Francisco Maldonado de Silva, residente en la ciudad de la Concepción en el reino de Chile, fue prendido por la Inquisición en 1627 y remitido a la Ciudad de los Reyes donde padeció un largo proceso (Böhm; Wachtel 47-71). Durante los años de su prisión redactó numerosos escritos apologéticos y de controversia, de los que lamentablemente solo nos han llegado fragmentos. Entre estos los más importantes son un cuadernillo y un pasaje de la carta escrita a la sinagoga de Roma.

El cuadernillo fue conservado en el expediente remitido a la Suprema como un ejemplo de los muchos que redactó. En este texto, Maldonado trata fundamentalmente dos aspectos cuya matriz teológica se encuentra en pasajes del Antiguo Testamento (Böhm 295-301): El primero se relaciona con el Mesías y su vinculación al rey David, porque "nombres propios se usurpan en las Escrituras por patronímicos, luego el nombre de David se puede entender por tal y aplicar a Cristo que fue hijo suyo..."; el segundo a la calidad de Jesús de Nazaret como Hijo de Dios, pues "Dios para conocerse y entenderse y comprehender su divina essencia, haze concepto de si mesmo y en este acto ay concebido y concibiente...". Si bien -en este segundo caso- las citas bíblicas abundan, se trata de un tema tratado fundamentalmente según los argumentos del procedimiento escolástico. Este último factor evidencia la matriz cultural de Maldonado, quien había obtenido el grado de bachiller en la Universidad de San Marcos de Lima.

Por otra parte, la carta dirigida a la sinagoga romana (de la que existen dos versiones, Böhm 305-325) intenta proporcionar a sus correligionarios italianos sólidos argumentos que Maldonado ha desarrollado en sus polémicas con los inquisidores y que prueban irrefutablemente que el Mesías no es venido. Estos se construyen a partir de tres pasajes bíblicos que Maldonado refuta en su interpretación cristiana tradicional: 1) la profecía de Ageo II sobre el Deseado; 2) el Salmo CIX ("Dijo el Señor a mi señor siéntate a mi diestra") "... de lo cual se evidencia que David tiene otro superior a parte de Dios que es su Señor..."; 3) y el texto de Daniel IX sobre la destrucción del Templo como castigo, que se mantiene hasta el presente, al pueblo deicida.

Pero quizás la fuente más relevante de documentación relativa al empleo de textos veterotestamentarios proceda del famoso judaizante novohispano Luis de Carvajal, quien adoptará, durante su primera prisión inquisitorial, el nombre de Joseph Lumbroso. Este individuo, luego de esta primera prisión y reconciliación de vehementi en el Santo Oficio de la Ciudad de México compuso un cuaderno manuscrito (Luis de Carvajal 1594-1596) utilizado luego por los inquisidores como materia de prueba en el segundo proceso. Se trata de una composición que representa una importantísima fuente para conocer los principios que animan su pensamiento así como el contexto cultural y religioso en el que se encuentra inmerso.

\footnotetext{
3 Luego de su segundo proceso en 1605, Diego Díaz Nieto solicita licencia a la Inquisición para poder embarcarse rumbo a Italia, el que por supuesto es denegado (Liebman 1971: 240).
} 


\section{Joseph Lumbroso}

La bibliografía referente a Luis de Carvajal (alias Joseph Lumbroso) y su familia es muy abundante (Liebman; Toro La familia; Uchmany; Toro Los judíos; Bodian 47-78; Cohen; Temkin). En el contexto de este artículo me ahorro profundizar en los acontecimientos fundamentales de su vida remitiendo al siguiente esquema biográfico compuesto a partir de su propia autobiografía y de los autos inquisitoriales seguidos contra él y su familia:

\begin{tabular}{|c|c|}
\hline \multirow[t]{2}{*}{1566} & Nace en Benavente (España) como hijo de padres portugueses \\
\hline & Estudia con los jesuitas (latín, gramática, retórica) \\
\hline 1580 & Travesía desde Sevilla a Nueva España junto con su familia \\
\hline 1584 & Muere su padre Francisco Rodríguez de Matos en México \\
\hline 13-III-1589 & Su hermana Isabel de la Cueva es arrestada por la Inquisición \\
\hline $9-V-1589$ & Luis es arrestado junto con su madre \\
\hline $12-\mathrm{V}$ a $4-\mathrm{VII}$ & Audiencias inquisitoriales \\
\hline 27-VII-1589 & Lectura de los cargos contra Luis \\
\hline 7-VIII-1589 & Luis es puesto en tormento (visiones mesiánicas) \\
\hline 7-VIII a 6-II & Confesiones de Luis \\
\hline $8-X I-1589$ & Primera sentencia \\
\hline $15-I-1590$ & Nueva acusación en su contra \\
\hline $6-I I-1590$ & Segunda sentencia \\
\hline 24-II-1590 & $\begin{array}{l}\text { Auto de Fe en que comparece la familia (reconciliado de } \\
\text { vehementi) }\end{array}$ \\
\hline \multirow[t]{2}{*}{ 5-III-1590 } & Es puesto en libertad \\
\hline & Destinado al Hospital de San Hipólito \\
\hline \multirow[t]{2}{*}{1591} & Destinado al Colegio de Santa Cruz de Tlatelolco \\
\hline & Accede a una Biblia de Vatablo, al Oleastro y a otros libros 4 \\
\hline$X-1594$ & Compra el perdón para él y su familia \\
\hline $1594-96$ & Escribe sus memorias \\
\hline $1-I I-1596$ & Es arrestado por segunda vez \\
\hline $8-X I I-1596$ & Luis de Carvajal muere en la hoguera \\
\hline
\end{tabular}

Fuentes: Luis de Carvajal, 1594-1596; Proceso Francisca de Carvajal 1589; Proceso Luis de Carvajal 1589; Proceso Mariana de Carvajal 1596.

4 Estas obras, que se encontraban, al parecer, en poder de fray Pedro de Oroz en el Colegio de la Santa Cruz de Tlatelolco, representan fuentes fundamentales para comprender el sustrato textual que nutre a Luis de Carvajal (así lo refiere, por ejemplo, Mariana de Carvajal en su testimonio ante la Inquisición, Proceso Mariana de Carvajal 1596: 307v). La llamada Biblia de Vatablo (Biblia Sacra cvm dvplici translatione, 1584) consiste en una obra editada originalmente en Paris en 1545 y reimpresa en Salamanca en 1584 (sin bien con la 
Si bien, como se observa en el esquema anterior, Luis de Carvajal había nacido en la villa de Benavente, provincia de Zamora, en Castilla la vieja, durante toda su vida fue identificado como portugués debido a la procedencia de sus padres (su madre Francisca Núñez de Carvajal, de familia de cristianos nuevos, había nacido en Mogadouro, región de Trás-os-Montes, Portugal) 5 .

En el cuaderno manuscrito, confeccionado por Luis de Carvajal probablemente entre 1594 y 1596 , el empleo de pasajes bíblicos infiltra prácticamente todo el documento. A grandes rasgos, resulta posible elaborar el siguiente esquema en cuanto a los contenidos de esta importante fuente y el modo como incorpora textos tomados de las Escrituras:

\begin{tabular}{|l|r|l|}
\hline \multicolumn{1}{|c|}{ Sección } & Fojas & \multicolumn{1}{|c|}{$\begin{array}{c}\text { Contenido procedente } \\
\text { de la Biblia hebrea }\end{array}$} \\
\hline 1) Memorias autobiográficas & 44 & $\begin{array}{l}\text { Con citas bíblicas explícitas e } \\
\text { implícitas }\end{array}$ \\
\hline $\begin{array}{l}\text { 2) Los artículos de nuestra } \\
\text { sagrada fe }\end{array}$ & 1 & $\begin{array}{l}\text { Los } 13 \text { artículos de } \\
\text { Maimónides }\end{array}$ \\
\hline 3) Los X mandamientos & 4 & Texto latino (Biblia de Vatablo) \\
\hline 4) Modo de llamar a Dios & 43 & $\begin{array}{l}\text { Con citas bíblicas explícitas e } \\
\text { implícitas }\end{array}$ \\
\hline $\begin{array}{l}\text { 5) Oraciones de personajes } \\
\text { bíblicos }\end{array}$ & 30 & $\begin{array}{l}\text { Extractadas del Antiguo } \\
\text { Testamento }\end{array}$ \\
\hline $\begin{array}{l}\text { 6) Mercedes hechas a Joseph } \\
\text { Lumbroso }\end{array}$ & 2 & $\begin{array}{l}\text { Especie de resumen de la } \\
\text { autobiografía }\end{array}$ \\
\hline
\end{tabular}

aprobación de la Inquisición la que enseguida es revocaba). En ella se incluían tres textos fundamentales: en una primera columna el de la Vulgata de Jerónimo (única versión considerada canónica por el Concilio de Trento); en una columna paralela (a modo de sinopsis) una nueva versión latina de los originales hebreos y griegos, reputada particularmente cercana al texto original y redactada en un latín al gusto humanista por el agustino italiano Santes Pagnini; y una tercera columna de citas (scholii) al pie de página, trabajo llevado a cabo por Francisco Vatablo, donde se concede gran espacio al comentario y explicación del texto hebreo, incluyendo vocablos impresos en dicha lengua, lo que representa una ostensible rareza en el espacio literario hispano durante este período. De esta obra copió Joseph Lumbroso el texto de los diez mandamientos, insertado al inicio de la sección devocional, y no de la Vulgata. Por otra parte el Commentaria in Pentatevchvm Mosi (Jerónimo de Oleastro 1588), conocido como el Oleastro, incluía el texto de los 13 artículos de Moshe ben Maimón (Maimónides). Respecto de esta obra escribe Joseph Lumbroso en sus memorias: "... también el tiempo que le sobraba después de la lección de los estudiantes lo ocupaba el fraile en sacarle las moralidades de Oleastro sobre el Pentatheuco en orden y tablas por el alfabeto, el cual ejercicio era tan conforme a su inclinación, y buen deseo, que si diera por él la sangre no lo pagaba, sea el S[eño]r bendito y ensalzado que ansi ayuda a los buenos deseos; en este libro le descubrió el S[eño]r los santos trece artículos y fundamentos de nuestra fe y religión cosa no sabida ni oída en las tierras de captiverio ..." (Luis de Carvajal, 1594-1596: sin foliar).

5 Acerca del fenómeno de la persistencia de la identidad portuguesa en tierras del rey de España consultar: Huerga Criado, 1993; Schreiber 1994. 


\begin{tabular}{|l|r|l|}
\hline \multicolumn{1}{|c|}{ Sección } & Fojas & \multicolumn{1}{|c|}{$\begin{array}{c}\text { Contenido procedente } \\
\text { de la Biblia hebrea }\end{array}$} \\
\hline 7) Fragmentos & 1 & $\begin{array}{l}\text { Bendición para la venida del } \\
\text { Mesías y otras }\end{array}$ \\
\hline 8) Términos hebreos & 1 & $\begin{array}{l}\text { Calendario de fiestas, meses y } \\
\text { números }\end{array}$ \\
\hline 9) Salmos XC, XCII y CXXXVII & 2 & $\begin{array}{l}\text { En latín (junto con } 3 \text { oraciones } \\
\text { en portugués) }\end{array}$ \\
\hline $\begin{array}{c}\text { 10) Principios de los } \\
\text { mandamientos de la ley }\end{array}$ & 2 & $\begin{array}{l}\text { Índice en portugués del libro } \\
\text { del Éxodo }\end{array}$ \\
\hline
\end{tabular}

Fuente: Luis de Carvajal, 1594-1596.

El recurso a textos bíblicos (todos ellos tomados del Antiguo Testamento) es profuso en los siguientes pasajes: en la autobiografía, en la sección dedicada a los diez mandamientos, en el Ordo de oración, en los largos pasajes que reproducen oraciones de personajes paradigmáticos de la tradición de Israel y en los tres salmos reproducidos al final del librillo.

Antes de proceder al análisis diferenciado de las secciones, es importante mencionar que, si bien en la actualidad el documento en estudio se presenta como una unidad encuadernada en el formato de un libro becerro, es evidente que la sección de las llamadas Memorias (que se compone de 44 fojas que no se encuentran foliadas) representó, originalmente, un texto independiente del bloque titulado Modo de llamar a Dios y ejercicio devotísimo de oración (se trata de 86 fojas que sí se encuentran foliadas) que representa, a todas luces, una variante personal, confeccionada por Joseph, de los oracionales (órdenes de oración o siddurim) usuales para el empleo, por parte de los devotos, en las juderías de las tierras libres y que a su vez se encuentran relacionados con los breviarios empleados en la tradición de la Iglesia Romana (Orden de los cinco Tahaniot; Di Leone Leoni).

\section{Memoria autobiográfica como texto sacro}

La autobiografía de Joseph Lumbroso abunda en referencias a pasajes del Antiguo Testamento. Básicamente, el modo en que Luis de Carvajal incorpora sus alusiones se puede dividir en tres tipos: implícitas, explícitas y una fusión de ambas.

La fusión de citas implícitas y explícitas queda óptimamente retratada en el empleo del Salmo CXVII a lo largo de todo el texto. En este caso, el versículo emblemático del Salmo, cuya variante usual en el texto reza Confesemos a $D$. porque es bueno porque es sempiterna su misericordia, es repetido, reinterpretado y comentado como un mantra a lo largo de toda la narrativa de las memorias. Se convierte de esta manera en el leitmotiv y clave de interpretación en las que se ha de comprender toda la existencia 
del autor y su familia, así como la tabla de salvación a la que apela Joseph ante la precariedad de su situación y la amenaza constante del enemigo inquisitorial. Esta técnica de composición pretende, a mi juicio, proponer una lectura del relato autobiográfico bajo las categorías del texto sacro por excelencia, de manera que sus protagonistas, Joseph Lumbroso y su familia, sean sublimados al estrato de los profetas y patriarcas, como objeto especialísimo de la elección y de la misericordia divina. En este contexto, se ha de tener presente que el sustantivo misericordia (abreviado usualmente mỹa en el texto) representa probablemente el vocablo más usual en toda esta sección narrativa (al que se debería sumar el empleo del sustantivo merced, empleado de manera sinónima).

Por otra parte, las alusiones implícitas también recorren las 44 fojas de esta sección. Buen ejemplo son las citas que interpretan la situación de la familia Carvajal en la Nueva España a la luz del paradigma veterotestamentario de los cautiverios egipcio y babilónico. Así por ejemplo, el texto se inaugura, en la primera foja, con la expresión:

"De gravísimos peligros por el Señor librado Joseph Lumbroso de nación hebreo de los peregrinos de la occidental India y de los captivos, en reconocimiento de las recibidas mercedes y dones de la mano del muy alto..." (Luis de Carvajal, 1594-1596, sin foliar).

Así como en la conclusión del pasaje autobiográfico:

"... por estar el que esto ha escrito todavía en tierras de captiverio, aunque en vísperas de salir con la ayuda y favor del altísimo y fuertísimo Adonay Dios de Israel de uno de los mayores y más peligroso captiverio que gente de nuestra nación ha padecido..." (Luis de Carvajal, 15941596, sin foliar).

Especialmente la conclusión del bloque autobiográfico parece, a la luz del texto bíblico, pretender interpretar la anhelada partida de la Nueva España hacia las juderías italianas (algo que nunca sucederá) como una especie de nuevo éxodo y retorno del exilio babilónico.

En esta misma línea funcionan las repetidas alusiones implícitas al ciclo del patriarca José (Génesis XXXVII-L) y al ciclo salomónico (1 Reyes III-X). Ambas figuras, el patriarca José y el rey Salomón, en una suerte de simbiosis, se convierten en prototipos de Joseph Lumbroso: ambos representan el paradigma del sabio israelita que aparece como ungido e instituido por Dios para demostrar entre las naciones extranjeras (Egipto y los circunvecinos de Israel) la superioridad del pueblo escogido.

Contemporáneamente resulta posible encontrar varios pasajes que son citados explícitamente al costado del texto, según el uso corriente en obras impresas contemporáneas al autor: 


\begin{tabular}{|l|l|}
\hline \multicolumn{1}{|c|}{ Cita } & \multicolumn{1}{c|}{ Texto } \\
\hline Génesis XVIII & Pecado de Onán hijo de Judá \\
\hline Salmo CVI & "erraron en la soledad sin camino" \\
\hline Éxodo XXXIV & $\begin{array}{l}\text { Prohibición de relacionarse sexualmente con } \\
\text { extranjeros }\end{array}$ \\
\hline Tobías III & Oración de Sara \\
\hline Salmo X & "orphano tu eris adiutor" \\
\hline Deuteronomio XXVIII & Maldiciones de la ley \\
\hline Salmo XXIII & "virga tua et baculus tuus ipsa me consolata sunt" \\
\hline
\end{tabular}

Fuente: Luis de Carvajal, 1594-1596.

Asimismo hay citas expresas de escenas bíblicas sin que se especifique el texto, como la referencia al relato del profeta Daniel en el foso o lago, en el léxico de Luis de Carvajal, de los leones (Daniel VI):

"... do por singularísima bondad del Señor Dios nuestro, vive él y los suyos, con no menor peligro que estuvo el Santo Daniel metido en el lago de leones, cerrándoles a estos que lo cercan El todopoderoso con milagro grande las crueles bocas con que si Dios nuestro Señor no lo estorbaba los despedazara" (Luis de Carvajal, 1594-1596, sin foliar).

Una vez más nos encontramos ante un uso textual tendiente a subliminar la experiencia del autor a la luz de la tradición bíblica: en este caso Joseph y su familia son protegidos por el Dios de Israel de las fauces de la Inquisición novohispana de la misma forma que Daniel lo fue de los feroces leones durante el exilio babilónico.

\section{Devociones bíblicas e identificación judaizante}

El sustrato devocional en la escritura de Joseph Lumbroso representa una modalidad de resistencia interna que apela a la reafirmación de la propia identidad religiosa. Se trata, en todo caso, de un tema complejo, no solo porque evidentemente nos encontramos ante una identidad sincrética, sino también porque implica interrogarse, en general, acerca de la posibilidad de una identidad judía unívoca, así como respecto de la naturaleza de las identidades religiosas y también por las complejas relaciones entabladas entre judaísmo y cristianismo a lo largo de la historia de las sociedades occidentales.

A grandes rasgos, la segunda sección del documento incluye una amalgama de textos seleccionados desde el Antiguo Testamento y organizados en función de su empleo en la oración comunitaria y personal. El núcleo central de este conjunto está representado por los siguientes pasajes: 


\begin{tabular}{|l|c|l|}
\hline \multicolumn{1}{|c|}{ Pasajes } & Fojas & \multicolumn{1}{|c|}{ Contenido } \\
\hline Los X mandamientos & 4 & $\begin{array}{l}\text { Texto latino según la Biblia de } \\
\text { Vatablo }\end{array}$ \\
\hline Modo devotísimo de oración & 43 & $\begin{array}{l}\text { Oracional: citas bíblicas explícitas } \\
\text { e implícitas }\end{array}$ \\
\hline $\begin{array}{l}\text { Textos de oraciones de personajes } \\
\text { bíblicos }\end{array}$ & 30 & $\begin{array}{l}\text { Extractos del Antiguo } \\
\text { Testamento }\end{array}$ \\
\hline Colecciones de fragmentos & 8 & $\begin{array}{l}\text { Textos misceláneos de finalidad } \\
\text { diversa }\end{array}$ \\
\hline
\end{tabular}

Fuente: Luis de Carvajal, 1594-1596.

Quizás de toda esta segunda sección el pasaje más relevante sea el Oracional (Modo de llamar a Dios y ejercicio devotísimo de oración). Se encuentra compuesto por dos tipos de materiales: un orden diario y oraciones para el día de las Perdonanzas ${ }^{6}$.

A continuación de esta sección se compilan oraciones atribuidas o relacionadas a diversos personajes del Antiguo Testamento, compuestas por textos procedentes en su gran mayoría de libros considerados en las tradiciones actuales como deuterocanónicos o abiertamente apócrifos. En este pasaje, más que en ningún otro, queda en evidencia el problema del texto canónico, el que se refleja en la inclusión de numerosos textos que no forman parte de la Biblia hebraica.

El propósito de este bloque se asemeja mucho al testimoniado por Luis de Lima ante el tribunal del Santo Oficio limeño en 1639. Quizás la diferencia más importante entre ambos es el medio de adquisición del texto: Luis de Carvajal traduce el texto latino de Santes Pagnini incluido en la Biblia de Vatablo, en cambio Luis de Lima adopta la versión romance de la obra de Hernando de Zárate. La finalidad de ambos parece ser la misma: disponer de oraciones devocionales atribuidas a individuos del pasado bíblico de Israel, cuya situación vital (Ester, Mardoqueo, Daniel, Manasés) sea coincidente con la experimentada contemporáneamente por los judaizantes en tierras de la Inquisición española.

Llevando a cabo una indexación de los pasajes bíblicos incluidos en este bloque, resulta posible elaborar, respetando el orden según Luis de Carvajal organiza sus textos, el siguiente esquema:

\footnotetext{
6 Acerca de esta sección me encuentro redactando un artículo especial, de pronta publicación, motivo por el que no me explayo respecto de esta materia en el presente estudio.
} 


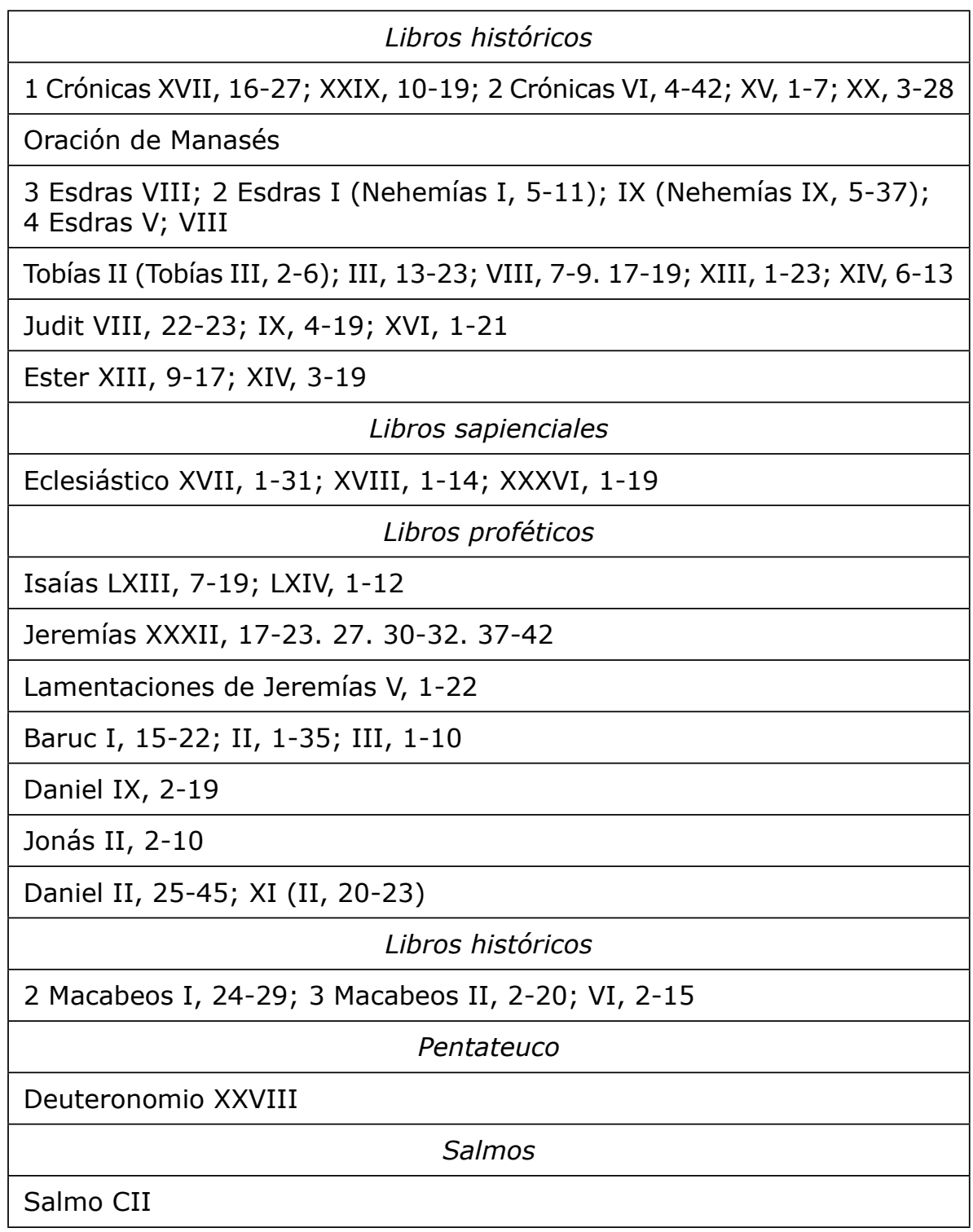

Fuente: Luis de Carvajal, 1594-1596.

El bloque comienza con textos procedentes de libros identificados al presente como históricos. Se trata de oraciones extractadas de los libros de Crónicas (oración de David luego de escuchar el oráculo de Natán, la bendición de David antes de morir, la oración de Salomón para la dedicación del Templo, la profecía de Azarías contra Asá, rey de Judá y la oración de Josafat) que concluyen con la oración de Manasés preso en la cárcel de Babilonia, la que se encuentra en la Vulgata a modo de apéndice y es considerada, en la actualidad, apócrifa tanto en los cánones cristianos como 
judíos7. En este contexto llama la atención que Luis de Carvajal haya empleado las versiones de Crónicas y no los textos paralelos (y originales) que se encuentran, entre otros, en 2 Samuel VII, 18-29 y 1 Reyes VIII, 22-53.

Luego incluye oraciones procedentes de los libros que la Vulgata atribuye al escriba Esdras: 2 Esdras (actualmente conocido como libro de Nehemías), 3 Esdras y 4 Esdras (ambos considerados apócrifos en todas las denominaciones). Del libro de Tobías, Joseph Lumbroso extrajo las oraciones de Tobías, Sara y Ragüel (a pesar que cita una de ellas como Tobías II en realidad se trata de Tobías III, 2-6). Del libro de Judit proceden Judit VIII, 22-23; IX, 4-19 y XVI, 1-21. Así como del libro de Ester copia la oración de Mardoqueo (Ester XIII, 9-17) y la oración de Ester (Ester XIV, 3-19). Por lo general todos estos personajes son identificados como santos (santo Esdras, Judit santa, santo Tobías, santa Sara, santo Mardoqueo, etc.).

Entre los libros sapienciales solo copia textos del Eclesiástico, además de un salmo al final de la recopilación. En el primer pasaje traducido del Eclesiástico (Eclesiástico XVIII, 1-14) es posible observar una técnica que se encuentra presente regularmente a lo largo de las traducciones que lleva a cabo Luis de Carvajal. Se trata de una hebreización del texto recibido de Pagnini, en este caso mediante la inserción del sustantivo Aholam como forma de traducir el atributo de Dios como "el eterno".

En el siguiente bloque se incluyen los textos extraídos de los libros proféticos: Isaías, el santo Jeremías, el libro de las Lamentaciones, Baruc, el santo Jonás y Daniel (incluyendo la oración de Azarías en el horno ardiendo). En este último profeta (Daniel IX, 2-19) también lleva a cabo una traducción hebreizante al insertar el vocablo Elohin (Dios) como traducción del término latino dominus.

A continuación traduce textos extractados de los libros de los Macabeos. Toda la sección concluye con un pasaje del Deuteronomio (capítulo XXVIII) y el Salmo CII cuya expresión central "Bendice anima mía a Adonay" es parafraseada continuamente.

En este contexto se ha de subrayar la forma en que Luis de Carvajal trabaja sus textos, la que incluye una alta dosis de personalización del pasaje original en aras de hacerlo converger de manera subjetiva en la experiencia personal del orante y en la situación en la que se encuentra. Un buen ejemplo de esta técnica de apropiación y reelaboración del texto bíblico se encuentre en al pasaje compuesto a partir de Jonás II, 2-10:

\footnotetext{
7 Aparece como apéndice al segundo libro de Crónicas en la Biblia de Vatablo: "Oratio Manafle regis Iuda, cum captus teneretur in Babylone".
} 


\begin{tabular}{|c|c|c|}
\hline Vulgata & $\begin{array}{c}\text { Santes Pagnini } \\
\text { (Vatablo) }\end{array}$ & Luis de Carvajal \\
\hline $\begin{array}{l}\text { Ad extrema montium } \\
\text { defcendi terrae vectes } \\
\text { concluferunt me in } \\
\text { aeternum: }\end{array}$ & $\begin{array}{l}\text { Ad fiffuras montium } \\
\text { defcenderam, terra } \\
\text { vectibus fuis perpetuò } \\
\text { me [concluferat,] }\end{array}$ & $\begin{array}{l}\text { bajé a los fines de los } \\
\text { montes, los cerrojos, } \\
\text { y candados de la } \\
\text { tierra me encerraron } \\
\text { para siempre me } \\
\text { habían encerrado para } \\
\text { siempre }\end{array}$ \\
\hline $\begin{array}{l}\text { \& fubleuabis de } \\
\text { corruptione vitã } \\
\text { meam, Domine Deus } \\
\text { meus. }\end{array}$ & $\begin{array}{l}\text { tu autẽ ab interitu } \\
\text { vitam meam reduxifti } \\
\text { ô Domine Deus meus. }\end{array}$ & $\begin{array}{l}\text { y tu Adonay mi Señor } \\
\text { Dios levantaste de la } \\
\text { corrupción mi vida } \\
\text { Adonay Señor Dios } \\
\text { mío }\end{array}$ \\
\hline $\begin{array}{l}\text { Cũ anguftiaretur in me } \\
\text { anima mea, Domini } \\
\text { recordatus Ivm; vt } \\
\text { veniat ad te oratio } \\
\text { mea ad tẽplum sanctũ } \\
\text { tuũ. }\end{array}$ & $\begin{array}{l}\text { Quam fermè animan } \\
\text { agerem, memor fui } \\
\text { Domini, venitã; oratio } \\
\text { mea ad templum } \\
\text { sanctitatis tue. }\end{array}$ & $\begin{array}{l}\text { cuando fue angustiada } \\
\text { mi ánima dentro de } \\
\text { mí me acordé del } \\
\text { Señor y oré a ti para } \\
\text { que llegase ante ti mi } \\
\text { ruego al templo santo } \\
\text { tuyo. }\end{array}$ \\
\hline $\begin{array}{l}\text { Qui cuftodiunt } \\
\text { vanitates fruftra, } \\
\text { mifericordiam fuam } \\
\text { derelinquunt. }\end{array}$ & $\begin{array}{l}\text { Qui obleruant funes } \\
\text { vanitatis beneficentiã } \\
\text { fuam derelinquunt. }\end{array}$ & $\begin{array}{l}\text { Los que guardan } \\
\text { vanidades en vano } \\
\text { desamparan su } \\
\text { misericordia, }\end{array}$ \\
\hline $\begin{array}{l}\text { Ego autem in voce } \\
\text { laudis immolabo tibi: } \\
\text { quaecunque voui } \\
\text { reddam pro salute } \\
\text { mea Domino. }\end{array}$ & $\begin{array}{l}\text { Ego autem voce } \\
\text { gratulatoria tibi } \\
\text { facrificabo, quaque } \\
\text { voui perfoluam: ipfa } \\
\text { falus Domini eft. }\end{array}$ & $\begin{array}{l}\text { y yo empero yo con } \\
\text { voz de alabanza } \\
\text { te ofreceré mis } \\
\text { sacrificios: todo lo } \\
\text { que prometí pagaré, y } \\
\text { cumpliré al señor por } \\
\text { la salvación que me } \\
\text { ha otorgado; }\end{array}$ \\
\hline \multirow[t]{2}{*}{$\begin{array}{l}\text { Et dixit Dominus pifci: } \\
\text { \& euomuit Ionam in } \\
\text { aridam. }\end{array}$} & $\begin{array}{l}\text { Mandauit autẽ } \\
\text { Dominus pifci, \& } \\
\text { euomuit Ionã in aridã. }\end{array}$ & $\begin{array}{l}\text { y mandándolo el } \\
\text { Señor a la ballena, y } \\
\text { echó en tierra a Jonás, }\end{array}$ \\
\hline & & $\begin{array}{l}\text { O Adonay mí Señor } \\
\text { Dios por amor de tu } \\
\text { santo nombre pon mi } \\
\text { ánima en seguridad } \\
\text { donde libre de este } \\
\text { mar profundo y } \\
\text { piélago peligroso te } \\
\text { pueda servir y adorar } \\
\text { entre tus siervos } \\
\text { amén. }\end{array}$ \\
\hline
\end{tabular}

Fuentes: Vulgata; Biblia Sacra cvm dvplici translatione, 1584; Luis de Carvajal, 1594-1596. 
La traducción de Luis de Carvajal de la oración que el profeta recita en el vientre de la ballena (en realidad se trata de un gran pez) evidencia la tendencia a seguir el texto de Santes Pagnini. Este fenómeno es evidente, por ejemplo, en la corrección que lleva a cabo al enmendar su primera versión ("me encerraron para siempre") por el pluscuamperfecto "me habían encerrado para siempre" que parece rendir mejor la variante me concluferat empleada por Pagnini a diferencia de la Vulgata (concluferunt me).

Al mismo tiempo, este pasaje es un buen ejemplo de la manera cómo Carvajal inserta una adición personalizante al concluir la oración, incluyendo una invocación que comienza por el apelativo Adonay (profusamente empleado en su redacción también como elemento hebreizante) y que implora del poder divino el rescate del "mar profundo y piélago peligroso" en el que se encuentra inmerso. Se trata, evidentemente, de una metáfora que alude al peligro mortal representado por el Santo Oficio novohispano.

\section{Conclusión}

Según refiere Carlo Ginzburg al concluir su estudio, el proceso inquisitorial que condujo a la muerte de Menocchio coincidió, en su etapa final, con el que se seguía en Roma contra el exfraile dominico Giordano Bruno (Ginzburg 147). Ese mismo año de 1600, en la Ciudad de México, se preparaba para afrontar la hoguera del Auto de Fe, Mariana de Carvajal (1577-1601), una de las últimas hermanas sobrevivientes de Joseph Lumbroso. Estas coincidencias no solamente apuntan hacia una coyuntura extremadamente álgida en materias religiosas al interior del orbe católico, sino que al mismo tiempo plantean una interrogante en relación con la repercusión que efectivamente tuvieron las doctrinas tan ardientemente defendidas por nuestros protagonistas. En efecto, la persona de Mariana de Carvajal representa, en el marco de la actividad de Joseph Lumbroso, un importante testimonio de la manera cómo la reconstituida y, hasta cierto punto, sincrética espiritualidad judaizante promovida por Joseph, representa un fenómeno en gran medida compartido de manera corporativa por una comunidad de individuos al interior de la diáspora "de los peregrinos en la occidental India".

La documentación procesada a lo largo de este estudio ha demostrado, al menos en forma incipiente, el importante papel desempeñado por los textos del Antiguo Testamento (tanto legislativos, narrativos, proféticos como sapienciales) en la conformación de identidad en círculos letrados judaizantes durante la modernidad temprana en la América hispana (Costigan).

Quizás uno de los desafíos mayores, inherentes a la situación de diáspo$\mathrm{ra}$, a que se vieron enfrentados los sujetos judaizantes fue precisamente el acceso a versiones textuales que coincidieran con sus propias perspectivas e intereses, y esto en el contexto de una férrea censura impuesta por el concilio de Trento desde un punto de vista canónico, respecto de las versiones del texto bíblico en circulación a lo largo del período. Es así como se observa una doble tendencia entre nuestros actores. Quienes (como Luis de Lima por ejemplo) no poseían la capacidad de interpretar o traducir las versiones latinas tienden a emplear ediciones romanceadas de pasajes veterotestamentarios accesibles mediante la literatura devocional hispana. Este tipo de 
material, que incluye textos como los Discrrsos de la paciencia Chriftiana de Hernando de Zárate, el Elpejo de confolacion de Tristes de Juan de Dueñas, y varias obras de fray Luis de Granada, representó una fuente extremadamente popular al interior de los círculos cristianos-nuevos ${ }^{8}$. Por otra parte, los letrados latinistas (como Luis de Carvajal o Francisco Maldonado de Silva) emplean versiones de la Vulgata (Maldonado de Silva) o, abiertamente, versiones conocidas por su cercanía al texto hebreo, como la traducción de Santes Pagnini incluida en la llamada Biblia de Vatablo o en el comentario al Pentateuco de Jerónimo de Oleastro.

En todo este proceso, resulta posible observar un sorprendente impulso traductor e interpretador enraizado en la necesidad de resistir a las proposiciones cristianas (y en particular a la amenaza ideológica representada por la Inquisición española). A fin de cuentas, la creación de un renovado metarrelato judaizante, que incluye textos considerados apócrifos en el judaísmo tradicional, en función de transfigurar la propia experiencia "en tierras de idolatría" representó para nuestros actores, empleando una metáfora bíblica, una suerte de arca de Noé en donde salvar las aguas del diluvio inquisitorial. Bajo esta perspectiva, se nos aparece Joseph Lumbroso como un nuevo patriarca José, cautivo en Egipto, como un sabio Salomón, enseñando a los gentiles, o como un santo profeta Daniel, en el foso de los leones, y su familia como un nuevo Israel, pueblo elegido de Adonay.

\section{Obras citadas}

Amiel, Charles. "Les cent voix de Quintanar: Le modèle castillan du marranisme" (II). Revue de l'Histoire des Religions 218 (2001): 487-577.

Biblia de Ferrara. Ferrara: Abraham Usque, portugués, y Yom-Tob Atias hijo de Levi Atias, español, impresores, en 14 de Adar 5313 (1553).

Biblia Sacra cvm dvplici translatione, \& Scholijs Francifci Vatabli, nunc denuò à plurimis, quibus fcatebant, erroribus repurgatis, doctifsimorum Theologorum, tam almae Vniuerfitatis Salmanticenfis, quàm Complutenfis iudicio: ac Sanctae \& generalis Inquifitionis iuffu. Vols. I-II. Cum Priuilegio Hifpaniarum Regis. Salmanticae: apud Gasparem à Portonariis fuis \& Gulielmi Rouillij Benedictique Boierij expenfis, 1584.

Bodian, Miriam. Dying in the Law of Moses. Crypto-Jewish Martyrdom in the Iberian World. Bloomington-Indianapolis: Indiana University Press, 2000.

Böhm, Günter. Historia de los judíos en Chile, volumen 1, Período Colonial, El bachiller Francisco Maldonado de Silva, 1592-1639. Santiago: Editorial Andrés Bello, 1984.

Boynton, Susan \& Reilly, Diane J. Ed. The Practice of the Bible in the Middle Ages. Production, Reception, and Performance in Western Christianity. New York: Columbia University Press, 2011.

Carvajal, Luis de. Cuaderno manuscrito de Luis de Carvajal (alias Joseph Lumbroso), 1594-1596, disponible en http://pudl.princeton.edu/objects/s7526g29j. Manuscrito en formato digital.

8 Por este motivo Charles Amiel denomina la obra de Juan de Dueñas "une encycplopédie du judaïsme" (Amiel 542-534). 
Castillo Gómez, Antonio. "Pasiones solitarias. Lectores y lecturas en las cárceles inquisitoriales del Siglo de Oro". Revista de Estudios Ibéricos 3 (2006): 139-150.

Cohen, Martin A. The Martyr. Luis de Carvajal, a Secret Jew in SixteenthCentury Mexico. Albuquerque: University of New Mexico Press, 2001.

Costigan, Lucia Helena. Through Cracks in the Wall. Modern Inquisitions and New Christian letrados in the Iberian Atlantic World. Leiden-Boston: Brill, 2010.

Di Leone Leoni, Aron. "Il Sedur de Oraciones de mes di Yom Tob Atias (Ferrara 1552)". Sefarad 63 (2003): 104-111.

Ginzburg, Carlo. Il formaggio e i vermi. Il cosmo di un mugnaio del '500. Torino: Giulio Einaudi editore, 1976.

Hassán, Iacob M. Ed. Introducción a la Biblia de Ferrara. Actas del simposio internacional sobre la Biblia de Ferrara, Sevilla, 25-28 de noviembre de 1991. Madrid: Ediciones Siruela, 1994.

Huerga Criado, Pilar. En la raya de Portugal. Solidaridad y tensiones en la comunidad judeoconversa. Salamanca: Ediciones Universidad de Salamanca, 1993.

Liebman, Seymour B. Los judíos en México y América Central (fe, llamas e Inquisición). México-Madrid-Buenos Aires: Siglo veintiuno editores, 1971.

Montesinos, Fernando de. Auto de la Fe celebrado en Lima a 23 de enero de 1639. Madrid: En la imprenta del Reyno, 1640.

Oleastro, Jerónimo de. Commentaria in Pentatevchvm Mosi, hoc est, in qvinqve primos bibliorvm libros. Quibus iuxta M. Sanctis Pagnini Lucenfis, ordinis Praedicatorum, interpretationem, Hebraïca veritas cùm ad genuinum Literae fenfum, tùm ad mores informandos, ad vinguen enucleatur. A R. P. Fratre Hieronymo ab Oleastro. Lvgdvni, apud Petrvm Landry, Cum priuilegio Regis, 1588.

Orden de los cinco Tahaniot. Del año, sin boltar de vna a otra parte, los quales son. El Tahanit de Tebet, el de Ester, el de dezisiete de Thamuz, el de Ab, y el de Guedaliáh. Ámsterdam: Estampado por orden de los señores Efraim Bueno, y Yonah Abravanel. En casa de Menasseh ben Israel. Año 5390 (1630).

Proceso inquisitorial contra Francisca de Carvajal, 1589, Archivo General de la Nación (México), Instituciones Coloniales, Inquisición, vol. 1488, exp. 1, fs. 1-230. Manuscrito.

Proceso inquisitorial contra Luis de Carvajal, 1589, Archivo General de la Nación (México), Instituciones Coloniales, Inquisición, vol. 1487, exp. 2, fs. 12-232. Manuscrito.

Proceso inquisitorial contra Luis de Lima, 1639-1666, Archivo Nacional de Madrid, Consejo de Inquisición, Libro 1031, fs. 213-225. Manuscrito.

Proceso inquisitorial contra Mariana de Carvajal, 1596, Archivo General de la Nación (México), Instituciones Coloniales, Inquisición, vol. 1490, exp. 3, fs. 1-349. Manuscrito.

Pulido Serrano, Ignacio. "Converso Complicities in an Atlantic Monarchy: Political and Social Conflicts behind the Inquisitorial Persecutions". The Conversos and Moriscos in Late Medieval Spain and Beyond, Volume 3, Displaced Persons. Eds. Kevin Ingram \& Juan Ignacio Pulido Serrano. Leiden-Boston: Brill, 2015. 117-128.

Révah, Israël S., "Les Marranes". Revue des Études Juives 118 (1959-1960): 30-77. 
Reventlow, Henning Graf. The Authority of the Bible and the Rise of the Modern World. Philadelphia: Fortress Press, 1985.

Saraiva, António José. Inquisição e Cristãos-Novos. Lisboa: Editorial Estampa,

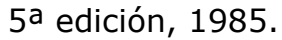

Saraiva, António José, The Marrano Factory. The Portuguese Inquisition and Its New Christians, 1536-1765, Translated, Revised and Augmented by H.P. Salomon and I.S.D. Sassoon. Leiden-Boston-Köln: Brill, 2001.

Schaposchnik, Ana E. The Lima Inquisition. The Plight of Crypto-Jews in Seventeenth-Century Peru. Madison-London: The University of Wisconsin Press, 2015.

Schreiber, Markus. Marranen in Madrid, 1600-1670. Stuttgart: Franz Steiner Verlag, 1994. Impreso.

Temkin, Samuel. Luis de Carvajal. The Origins of Nuevo Reino de León. Santa Fe: Sunstone Press, 2011.

Toro, Alfonso. La familia Carvajal. Estudio histórico sobre los judíos y la Inquisición de la Nueva España en el siglo XVI, basado en documentos originales y en su mayor parte inéditos, que se conservan en el Archivo General de la Nación de la ciudad de México. México: Editorial Patria, 1977.

Toro, Alfonso. Comp. Los judíos de la Nueva España. Documentos del siglo XVI correspondientes al ramo de Inquisición. México: Archivo General de la Nación \& Fondo de Cultura Económica, 1993.

Uchmany, Eva Alexandra. La vida entre el judaísmo y el cristianismo en la Nueva España, 1580-1606. México: Archivo General de la Nación, 1992.

Vega, María José. "Lecturas criptojudías en los siglos áureos: el Ramillete de flores", Studia Aurea 4 (2010): 37-51.

Wachtel, Nathan. La fe del recuerdo. Laberintos marranos. Buenos Aires: Fondo de Cultura Económica, 2007.

Zárate, Hernando de. Discvrsos de la paciencia Chriftiana, Muy prouecholos para el confuelo de los afligidos en qual quiera aduerfidad: Y para los predicadores de la palabra de Dios. Compueftos por el Maeftro fray Hernando de Çarate, de la orden de San Auguftin de la prouincia de Andaluzia. Imprefro en Alcala, en cala de Iuan Iñiguez de Lequerica, con priuilegio Real, Año 1592. 